\section{Selten, aber unschön: Komplikationen durch Filler lassen manchen alt aussehen}

Wer sich Filler zum Volumenaufbau unter die Haut spritzen lässt, hofft auf jugendlichere Konturen. Knoten, Entzündungen und Nekrosen sind da eher unerwünscht. Manchmal treten sie trotzdem auf.

$\bigcup S-a r$ S-amerikanische plastische Chirurgen haben die Patientendaten des Williams Rejuva Center in New York durchforstet und 2.089 Behandlungen mit dermalen Fillersubstanzen analysiert. 1.047-mal kam Hyaluronsäure, 811-mal Poly-L-Lactid und 231-mal Kalzium-Hydroxylapatit zum Einsatz. Unerwünschte Folgen traten in 14 Fällen auf, was einer Quote von $0,7 \%$ entsprach. Die Substanzen mit ihren Komplikationsraten und Komplikationen im Einzelnen:

-Hyaluronsäure (0,2\%): entzündliches

Granulom an der Lippe bei einem Patienten; Tyndall-Phänomen nach Injektion zur Behandlung der Tränenrinne _Polymilchsäure(0,7\%): fünf Patienten mit subkutanen Knoten, ein Fall von perioraler Dermatitis

- Hydroxylapatit (2,6\%): Drei Patienten erlitten phlegmonöse Entzündungen im behandelten Bereich, einer davon zweimal im Abstand von sieben Monaten; ein Patient entwickelte einen sichtbaren submukösen Knoten im Bereich der Wangenschleimhaut; ein Patient trug eine Teilgewebsnekrose am Übergang des Nasenflügels zum Gesicht nach einer Injektion in die Melolabialfalten davon.

Volumenverlust sei ein integraler Bestandteil des Alterungsprozesses, schreiben die US-Plastiker. Umgekehrt wirke der Wiederaufbau von Gewebefülle verjüngend. Das neu gewonnene Volumen sollte freilich nicht in Knoten, Granulomen oder entzündlichen Schwellungen bestehen.

Fazit: „Injizierbare Filler sind nicht risikolos", betonen die Mediziner im Resümee ihrer Studie. Immer mehr Menschen bedienten sich der ästhetischen

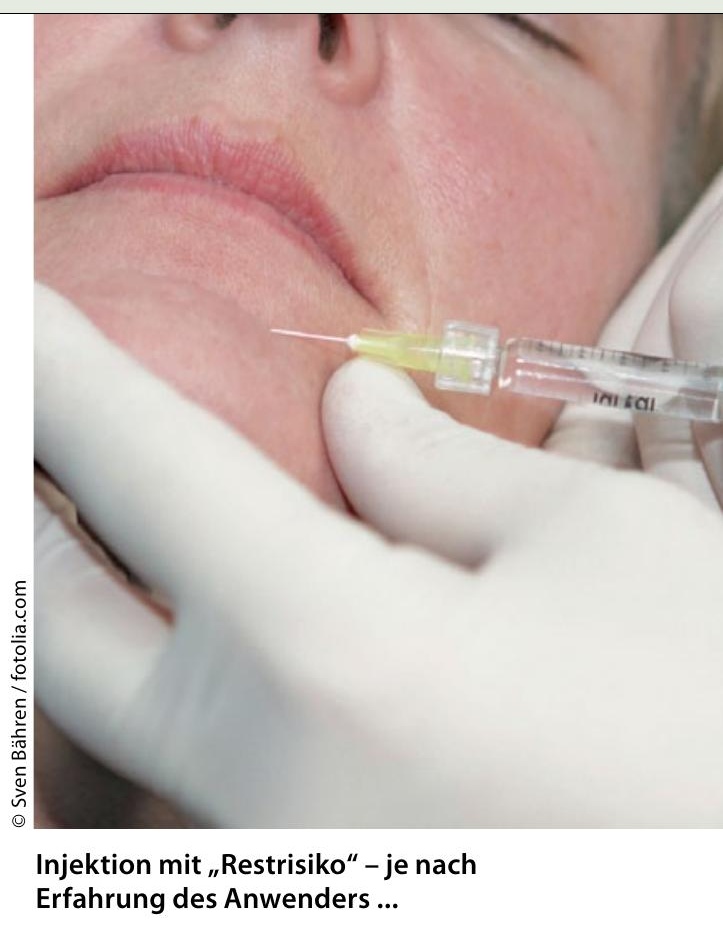

Medizin. Weil sie dabei oft Ärztehopping betrieben, würden Komplikationen zu selten bemerkt und behandelt. Es mangele an ausreichender Nachbeobachtung - und bei vielen Ärzten auch an Erfahrung.

Dr. Robert Bublak

Daines SM, Williams EF. Complications Associated With Injectable Soft-Tissue Fillers. JAMA Facial Plast Surg 2013 Mar 28; Epub ahead of print

\title{
Nasen-Piercing mit negativen Folgen
}

\section{Wer sich im Bereich der Nase ein Piercing setzen lassen will, sollte ausführlich über bestehende Risiken aufgeklärt werden. Das Spektrum an Komplikationen ist groß.}

Ein ne Gefährdung durch Nasen-Piercing ist vor allem nach Verwendung nicht steriler Instrumente, ungenügender Nachsorge oder durch fehlerhafte Techniken gegeben. So wurde über Infektionen mit Staphylococcus aureus, Pseudomonas aeruginosa sowie Hepatitis-Viren berichtet. Daneben kommt es immer wieder zu Blutungen oder zur Ausbildung von Narben und Keloiden. Auch zu Granulomen und sogar Basalzellkarzinomen im Zusammenhang mit einem Piercing gibt es Publikationen.

Auf die Problematik perforierter Knorpel haben auch Strieth und Berghaus hingewiesen. Hier besteht die Gefahr eines Septumhämatoms, einer Pe- richondritis oder Abszessbildung, dabei können letztlich auch Defomierungen resultieren. Auch eine behinderte Nasenatmung sowie auffällige Atemgeräusche sind möglich [Strieth $\mathrm{S}$, Berghaus A. MMW-Fortschr Med 2006; 41: 41-3].

Einige Länder wie Neuseeland oder Frankreich haben mit allgemeinen Richtlinien versucht, möglichen Komplikationen im Vorfeld zu begegnen. Ein rechtsfreier Raum existiert allerdings auch in Deutschland nicht. Anbieter von Piercings müssen sich hinsichtlich der Materialien an EU-Richtlinien orientieren. Zudem ist das Lebensmittel- und Bedarfsgegenstände-Gesetz (LMBG) zu beachten. Für den besonderen Schutz von Minderjährigen gelten die Paragraphen 106,107 und 113 des Bürgerlichen Gesetzbuchs.

Darüber hinaus hat der europäische Berufsverband für professionelles Piercing (EAPP) einen Anforderungskatalog mit „Richtlinien für die Durchführung und Hygiene im professionellen Piercingstudio für zertifizierte EAPP-Mitglieder" erstellt.

Fazit: Da Nasenringe möglicherweise irgendwann den Beliebtheitsgrad von Ohrringen erreichen, müssen Piercer wie Verbraucher vorbereitet sein, so die Autoren. Am wichtigsten ist eine verbesserte Aufklärung über sichere Techniken, hygienische Vorsichtsmaßnahmen und potenzielle Risiken.

Dr. Christine Starostzik

Ladizinski B et al. Nose piercing: historical significance and potential consequences. JAMA Dermatol 2013; 149: 142 